Biology of Drosophila

Edited by M. Demerec. Pp. $x+632$. (New York : John Wiley and Sons, Inc. ; London : Chapman and Hall, Ltd., 1950.) 80s, net. A BOOK with this title ought to be a summary habits of all the numerous species of Drosophila, seen in relation to insect life as a whole, and to the special roles of this genus as an introduced pest into temperate climates and as a laboratory animal. This one is not. Only the last chapter, "Collection and Laboratory Culture" by Warren P. Spencer, concerns the insect as a whole, and contains much practical advice to all who need to trap flies and rear them in the laboratory. The other six chapters, "Normal Spermatogenesis" by Kenneth W. Cooper, "Early Embryology" by B. P. Sonnenblick, "Histogenesis, Organogenesis and Differentiation in the Embryo" by D. F. Poulson, "Postembryonic Development" by Dietrich Bodenstein, "External Morphology of the Adult" by G. F. Ferris and "Internal Anatomy and Histology" by Albert Miller, deal only with bits of the animal, and of course refer almost exclusively to D. melanogaster.

The real purpose of this symposium is to provide a handbook of what is considered 'normal' in the morphology, histology, embryology and postembryonic development of $D$. melanogaster, a standard of reference by which the vast amount of experimental work on this fly can be assessed. Deciding what is 'normal' is necessarily a strongly subjective process; but the work is extremely well documented and includes some references up to 1947 . The numerous illustrations, including many excellent photomicrographs, are very clearly lettered, and the account of post-embryonic development includes a chronological table of events as they take place in the 'normal' fly at $25^{\circ}$ C. G. F. Ferris's section on external morphology presents a personal point of view that diverges considerably from generally accepted views, especially in trying to avoid such apparent discontinuities as exist between the mouthhooks of the larva and the mouthparts of the imago.

The geneticist, the embryologist and the insect morphologist will all find this symposium a valuable guide into collateral fields of study, while the general entomologist, and especially the dipterist, will welcome such an exhaustive study of one species. It is a pity about the title.

H. OLdroyd

\section{Introduction to Electron Optics}

The Production, Propagation and Focusing of Electron Beams. By V. E. Cosslett. Second edition. Pp. xvi $+294+8$ plates. (Oxford: Clarendon Press; London: Oxford University Press, 1950.) 27s. 6d. net.

TWHE second edition of Dr. Cosslett's well-known book is a photographic reprint from the first edition, with some mis-statements and misprints corrected. The text thus differs little from the original, but a series of notes on more recent work has been added, as well as some numerical examples on the more theoretical chapters. The first edition appeared before many of the advances made during the Second World War were made public. It is therefore regrettable that the final third of the book, dealing with applications of electron optics in research and industry, has not been rewritten to include the progress made in electron microscopy, particle acceleration and the generation and amplification of centimetre waves. However, the book is written mainly for students and those commencing research work, and it must be judged in this light. The first edition was always highly regarded as being an excellent introductory text, and the new edition should maintain this good reputation.

\section{Orkney}

By Hugh Marwick. (County Books Series.) Pp. viii $+287+49$ plates. (London : Robert Hale, Ltd., 1951.) 15s. net.

TO part of Scotland is richer in prehistoric remains 1 than the islands of the Orkney group. Both habitations and burial places are numerous, and all seem to begin in Neolithic times. These matters are described and discussed in this book, and well illustrated by photographic plates. But the volume is not only archrological. All aspects of the islands are treated, though the natural history perhaps has least notice. There are, however, other books on these aspects. Agriculture gets adequate notice. The islanders depend almost wholly on this for their prosperity, their exports being eggs and cattle, and some lobsters. There are no industries, though the manufacture of tweed is beginning. Population has been falling for the past hundred years, and only twenty-seven of the sixty islands have any inhabitants ; and several have only one farm or a lighthouse. The book has an adequate map.

\section{The Land of Britain}

Its Use and Misuse. By L. Dudley Stamp. Second edition. Pp. viiit 507. (London, New York and Toronto : Longmans, Green and Co., Ltd., in conjunction with Geographical Publications, Ltd., 1950.) $45 s$. net.

7 HIS valuable book, first published in 1948, has now been re-issued in what the publishers describe as a second edition; little if any change, however, seems to have been made in the text. The bibliography is unaltered and stops at 1946, although some valuable reports and books published since that date might well have found a place. Also there still remain the puzzling discrepancies between the official statistics of land utilization in England and Wales as published by the Ministry of Agriculture and those as quoted on p. 481 : up to 1939 the figures agree with those of the Ministry, but for 1940-46 they do not, and no explanation is given. Also the figures stop at 1946, but the later ones, which are very interesting, are available. A completed table brought up to date would have been very helpful; in no other readily accessible volume are these important statistics assembled on one page as they are here.

The need for a re-issue shows how widely the book has been appreciated. Nowhere else can the student find so full and authoritative an account of the land of Britain or so good a summary of the labours of the devoted band of workers who carried out the classical Land Utilization Survey on which it is based.

The original Survey was carried out in 1931 and 1932, and, since then, British agriculture has undergone profound changes. Would it be possible to repeat the Survey now that twenty years have elapsed, so as to have a full record of these changes ? The information would be invaluable for those whose task it is to direct the new agriculture, and there still remain a sufficient number of the old workers to ensure that the results would be comparable with those of the 1931 Survey. E. JoHN Russel 